REVIEW

\title{
Diagnosis and management of chronic pancreatitis
}

\author{
V Gupta, P P Toskes
}

Postgrad Med J 2005;81:491-497. doi: 10.1136/pgmj.2003.009761

Chronic pancreatitis represents a condition that is challenging for clinicians secondary to the difficulty in making an accurate diagnosis and the less than satisfactory means of managing chronic pain. This review emphasises the various manifestations that patients with chronic pancreatitis may have and describes recent advances in medical and surgical therapy. It is probable that many patients with chronic abdominal pain are suffering from chronic pancreatitis that is not appreciated. As the pathophysiology of this disorder is better understood it is probable that the treatment will be more successful.

See end of article for authors' affiliations

....................

Correspondence to:

Professor P P Toskes,

University of Florida,

Division of

Gastroenterology

Hepatology and Nutrition,

1600 SW Archer Road,

Room HD 602, PO Box

100214, Gainesville, FL

32610, USA; toskepp@

medicine.ufl.edu

Submitted

20 September 2004

Accepted

14 February 2005
C hronic pancreatitis is an inflammatory condition that results in permanent structural changes in the pancreas that ultimately leads to impairment of exocrine and endocrine function. ${ }^{1}$ This is the fundamental basis why patients with this disorder commonly present with abdominal pain or maldigestion, or both. Although pain is the cardinal feature of chronic pancreatitis, its presentation varies significantly among patients. The "classic" pain is located in the epigastrium, radiates to the back, is associated with oral intake, nausea, vomiting, and is relieved by sitting forward. Many patients fail to exhibit this "classic" pattern, however, and this is why chronic pancreatitis must be included in the differential diagnosis of any unexplained chronic abdominal pain. Unfortunately, the treatment of pain in these patients is difficult as it is often complicated by alcohol misuse, narcotic dependence, and psychological factors.

About $20 \%$ of patients with chronic pancreatitis present with endocrine or exocrine dysfunction in the absence of abdominal pain. ${ }^{2}$ Exocrine dysfunction leads to maldigestion causing patients to present with diarrhoea, steatorrhoea, and weight loss. Steatorrhoea typically occurs before protein deficiencies. Malabsorption of fat soluble vitamins and cobalamin (vitamin B12) may occur, although clinically significant vitamin deficiency is rare. ${ }^{3}$

The annual incidence of chronic pancreatitis has been estimated in several retrospective studies and ranges from 3 to 9 cases per 100000 population. ${ }^{4}$ The only prospective study to date estimated the incidence to be 8.2 cases per year per 100000 population. ${ }^{5}$ In most studies, alcohol misuse accounts for two thirds of all cases of chronic pancreatitis.

Large duct disease, most commonly associated with alcohol misuse, is well recognised by most physicians and diagnosed comparatively easily as virtually any diagnostic test will show large duct chronic pancreatitis. In the absence of radiological abnormalities or other imaging (ERCP, MRCP, CAT scan, ultrasound) abnormalities, it becomes imperative for physicians to recognise the presence of small duct pancreatitis. The typical tests used to diagnose large duct disease are often too insensitive to diagnose small duct disease. The disorder is poorly recognised by most clinicians for many reasons including a poor appreciation for the disorder and the unavailability of specialised testing at local centres. ${ }^{6}$ Given this, it is probable that the percentage of patients with chronic pancreatitis has been greatly underestimated and that a significant portion of patients with chronic abdominal pain may actually be suffering from small duct chronic pancreatitis.

\section{PATHOPHYSIOLOGY}

Chronic pancreatitis has numerous causes with chronic alcohol misuse responsible for most cases. While chronic alcohol misuse does represent about $70 \%$ of cases it is important for clinicians to recognise the other causes of chronic pancreatitis as well (table 1).

Although, these other causes are not as frequent as alcoholic and idiopathic chronic pancreatitis they warrant consideration. In particular the incidence of autoimmune pancreatitis has been found to be much greater than initially thought. The incidence seems to be increasing in some regions, particularly in Japan. ${ }^{7}$ However, it has been described in several countries in Europe as well as the USA and Korea suggesting that it is a worldwide entity. ${ }^{8}$

Chronic pancreatitis is a progressive disease process that causes irreversible pancreatic

\section{Table 1 Chronic pancreatitis causes}

\begin{tabular}{ll} 
Type & \% Of patients \\
\hline Alcohol induced & 70 \\
Idiopathic & 20 \\
Other & 10 \\
Cystic fibrosis & \\
Hypertriglyceridaemia & \\
Tumour & \\
Pancreatic resection & \\
Familial & \\
Congenital anomalies & \\
Tropical & \\
Autoimmune & \\
Genetic defects & \\
\hline
\end{tabular}

Abbreviations: CCK, cholecystokinin; $E R C P$, endoscopic retrograde cholangiopancreatography; $\mathrm{CT}$, computed tomography; EUS endoscope ultrasound, 
damage and is pathologically characterised by chronic inflammation and irregularly distributed fibrosis. Conversely, acute pancreatitis typically involves reversible damage that affects a significant portion of the pancreas. The two disorders probably involve different pathophysiological processes with recurrent bouts of acute pancreatitis usually not leading to chronic pancreatitis, however this remains controversial.

Chronic pancreatitis is a multifactorial disorder that is probably started by two distinct events. The first event is attributable to functional or mechanical causes of decreased bicarbonate secretion. Functional impairment may be caused by genetic factors such as cystic fibrosis transmembrane conductance regulator and serine protease inhibitor kazal type 1 gene mutations and mechanical obstruction by tumour, strictures, and sphincter of Oddi dysfunction. ${ }^{9}$ The second event involves the premature activation of pancreatic exocrine enzymes within the pancreatic gland leading to interstitial fat necrosis and haemorrhage. This, in turn, starts a sequence of perilobular fibrosis, duct distortion, and changed pancreatic secretion.

Various genetic abnormalities have also been sought to further characterise the disorder. Chronic pancreatitis has been thought to be associated with over-expression of fibroblasts and growth factors, increased interleukin 8 expression, and disorders in cholecystokinin (CCK) homoeostasis. These various factors, in conjunction, ultimately lead to irreversible damage to the organ..$^{10-12}$

\section{DIAGNOSIS}

It is imperative in the diagnosis of chronic pancreatitis that patients be differentiated into having either large or small duct disease. This is important as there are significant differences in regards to the clinical course, treatment, and outcomes. In evaluating patients with chronic pancreatitis, testing is typically centred upon diagnosing abnormal structure and abnormal function. Table 2 summarises the findings seen on testing in large duct and small duct chronic pancreatitis. As stated previously, the diagnosis of large duct disease is comparatively easy, with a variety of diagnostic tests yielding positive results.

To fully assess the benefits of any diagnostic test there needs to be a gold standard or reference against which the sensitivity and specificity of testing is measured and this has typically been pathological specimens. In the case of chronic pancreatitis, the organ is comparatively inaccessible and biopsies carry a high risk. The only such series to examine this is a Japanese series of 108 patients who underwent a hormone stimulation test and pancreatic wedge biopsy as a reference standard. There was a significant correlation between histological examination and peak bicarbonate concentration. In addition, during subgroup analysis of 29 patients who had had endoscopic retrograde cholangiopancreatography (ERCP) performed, it was found that the sensitivity of the stimulation test was greater than that of ERCP. ${ }^{13}$

The secretin stimulation test is the most sensitive and specific testing available for the diagnosis of chronic pancreatitis. ${ }^{14}$ It has, unfortunately, been underused secondary to a poor understanding of its role as well as the fact that it is invasive and only performed in about 10 medical centres in the USA. Previously, the typical testing for chronic pancreatitis had focused on structural findings that, while sensitive at diagnosing large duct disease, proved to be comparatively insensitive at diagnosing small duct disease. It is important to note that about $30 \%$ of patients with small duct disease who have had a normal or near normal ERCP will be found to have an abnormal secretin stimulation test. These near normal pancreaticograms include subtle changes in the side branches that are seen at the time of ERCP and whose significance varies significantly between endoscopists. Furthermore, in elderly patients these changes can be seen and are thought to be related to aging. ${ }^{15}{ }^{16}$ Our institutional experience is that secretin testing becomes positive when there is about $60 \%$ damage to the exocrine pancreas and ERCP findings suggestive of the disease occur with about $75 \%$ damage. Occasionally, the converse may be seen and patients may be found to have normal pancreatic stimulation testing and an abnormal pancreaticogram at the time of ERCP. This makes these tests not mutually exclusive, but, complementary in diagnosing chronic pancreatitis.

A discussion of the structural means of diagnosing chronic pancreatitis would be incomplete with discussing endoscopic ultrasound (EUS), which in recent years has emerged as a very sensitive test to aid in the diagnosis of chronic pancreatitis. The technology has a significant advantage over ERCP in that it is able to not only assess the intraductal system, but also the parenchyma. In addition it is safer, with the risk of post-ERCP pancreatitis being about $6.7 \%$ (range $1 \%-30 \%$ ) as compared with the risk of serious complications related to diagnostic EUS, which is estimated at $0.5 \% .{ }^{17} 18$ Table 3 summarises the EUS criteria for the diagnosis of chronic pancreatitis.

Various studies have examined the sensitivity and specificity of EUS in diagnosing chronic pancreatitis. When compared against ERCP there have been as high as 97\% sensitivity, $60 \%$ specificity, and $75 \%$ negative predictive value. ${ }^{19}$ When compared against the traditional gold standard of histological examination, however, these percentages falter further and have been shown to have a $78 \%$ sensitivity, $73 \%$ specificity when using four or more features for the diagnosis. ${ }^{20}$ In a preliminary study from our laboratory where EUS was compared with the secretin test EUS was shown to have a sensitivity of only $57 \%$ and a specificity of $64 \% .{ }^{21}$

Table 2 Features of large duct and small duct chronic pancreatitis

\begin{tabular}{|c|c|c|}
\hline Feature & Large duct & Small duct \\
\hline $\begin{array}{l}\text { Sex predominance } \\
\text { Diagnostic findings }\end{array}$ & Male & Female \\
\hline Secretin test & Abnormal & Abnormal \\
\hline Serum trypsinogen & Often abnormal & Typically normal \\
\hline $\begin{array}{l}\text { Diffuse pancreatic calcifications } \\
\text { on imaging }\end{array}$ & Frequent & Infrequent \\
\hline ERCP & Often considerably abnormal & Minimally abnormal to normal \\
\hline Natural history & & \\
\hline $\begin{array}{l}\text { Progression to steatorrhoea } \\
\text { Pain therapy }\end{array}$ & Frequent & Rare \\
\hline $\begin{array}{l}\text { Pancreatic enzymes } \\
\text { Surgical procedures }\end{array}$ & $\begin{array}{l}\text { Poor to fair response } \\
\text { Sometimes helpful }\end{array}$ & $\begin{array}{l}\text { Good to excellent response } \\
\text { Usually not indicated }\end{array}$ \\
\hline
\end{tabular}


Another preliminary study from the Mayo Clinic gave similar results. ${ }^{22} \mathrm{~A}$ second issue is the apparent overdiagnosing of chronic pancreatitis in patients who are shown to have normal pancreatic function testing and normal ERCP, but subtle changes on EUS. The actual accuracy of EUS to detect small duct chronic pancreatitis has yet to be fully defined.

Serum trypsinogen and fecal elastase are the tests of choice in patients with symptoms of malabsorption such as diarrhoea, steatorrhoea, and weight loss. If patients have enough damage to the exocrine pancreas to cause steatorrhoea and maldigestion, one of these tests will invariably be positive. It should be noted, however, that although both of these tests are excellent in detecting chronic pancreatitis with steatorrhoea, they do not consistently separate mild to moderate chronic pancreatitis from normals. In a study by Amann et al, all chronic pancreatitis patients with steatorrhoea had values of $<100 \mu \mathrm{m} / \mathrm{g}$ of stool, but more than half of the mild to moderate chronic pancreatitis subjects had fecal pancreatic elastase 1 levels within the normal range. ${ }^{23}$ Serum trypsinogen values of $<20 \mathrm{ng} / \mathrm{ml}$ have an accuracy of $95 \%$ in detecting severe pancreatic insufficiency, but this test is not very sensitive. ${ }^{24}$

In summary, to diagnose chronic pancreatitis with the wide variety of testing available the clinician must carefully select diagnostic testing that is relevant to the patients' symptoms. As stated earlier, in patients with symptoms of diarrhoea and steatorrhoea the initial testing should include a serum trypsinogen or fecal elastase as one of these tests will invariably be positive if severe exocrine dysfunction exists. In patients with chronic unexplained abdominal pain who are referred to institutions with secretin stimulation testing, typically basic radiological imaging (radiography or computed tomography) is performed first to rule out obvious large duct disease and after this, secretin testing. If the secretin stimulation test is positive then this obviates the need for diagnostic ERCP. This order of testing is safer, more sensitive, specific, and less expensive.

\section{MANAGEMENT OF MALABSORPTION}

Although complete correction of steatorrhoea is not commonly achieved, with appropriate treatment it can be controlled to restore a patient's fat absorption to an acceptable level, thereby allowing them to gain weight through a reduction in diarrhoea and steatorhoea. Patients do not develop steatorrhoea until their lipase level decreases to less than $10 \%$ of normal. Given this, the cornerstone of treatment has evolved around the exogenous replacement of lipase through the use of pancreatic enzymes that have been primarily from porcine sources.

The site of pancreatic enzyme delivery (duodenum or jejunum) does not seem to be as important for the release of lipase as it does for protease. This is because fat absorption occurs throughout the small intestine. Given this, patients with steatorhoea alone should be placed on two capsules of a potent high lipase enteric coated preparation before meals. If patients have an element of pain it will be necessary to treat

Table 3 Endoscopic ultrasonographic criteria for chronic pancreatitis

\begin{tabular}{ll}
\hline Ductal & Parenchymal \\
\hline Stones & Echogenic strands \\
Echogenic ductal walls & Echogenic foci \\
Irregular ductal walls & Calcifications \\
Stricture & Lobular contour \\
Visible side branches & Cyst \\
Ductular dilatation & \\
\hline
\end{tabular}

them with a non-enteric coated enzyme preparation but this will be discussed more extensively below.

\section{MANAGEMENT OF PAIN}

Although it has been suggested that the natural path of chronic pancreatitis is toward progressive glandular insufficiency and calcification with eventual pancreatic burnout and cessation of pain ${ }^{25}$ this has not been found to be the case. In 1995, 318 patients were followed up over a median of nine years and after this time period $50 \%$ of alcoholic patients and $73 \%$ of non-alcoholic patients still reported pain. ${ }^{26}$ Given this, it is unreasonable to passively monitor patients with pain from chronic pancreatitis in the hope of spontaneous pain resolution.

The treatment of chronic pain in patients with chronic pancreatitis can be frustrating for both clinicians and patients. The pathogenesis of the pain remains poorly understood, but has been thought to be associated with perineural inflammation, increased pressure in both large and small ducts, and in the pancreatic parenchyma, an abnormal feedback mechanism, or pancreatic carcinoma with duct obstruction. In addition, patients may develop the secondary complications of chronic pancreatitis such as a pseudocyst, duodenal obstruction, or duct obstruction that may exacerbate their pain. Lastly, these patients have a high incidence of dysmotility that may be worsening or causing their pain and that may be exacerbated by concurrent narcotic use.

Given the significant difficulty in treating patients with chronic pancreatitis, it becomes necessary to develop a systematic approach to the treatment of their pain. In patients with presumed pain from chronic pancreatitis it is important to first evaluate for the presence of large or small duct disease, as described above, as this will affect the treatment course. As well, secondary complications of chronic pancreatitis such as pseudocysts should be ruled out.

Although difficult, it is important for clinicians to avoid the use of narcotics analgesics in these patients. Unfortunately, narcotic dependence and addiction are common in these patients. Patients should be treated initially with a regimen of acetaminophen and non-steroidal anti-inflammatory drugs. After this, if necessary, this regimen may be supplemented with analgesics such as tramadol or propoxyphene. The us of narcotics typically only complicates the clinical picture in these patients and typically worsens or causes gastroparesis, which is common in these patients. ${ }^{27} 28$ It is our strong conviction that if the root cause of the pain is managed as described below, then narcotics may not be necessary.

\section{PANCREATIC ENZYMES}

Before discussing the use of pancreatic enzymes for the treatment of small duct chronic pancreatic pain it is important to understand the physiological mechanisms behind its use.

The exogenous replacement of pancreatic proteases is based upon the concept of feedback inhibition of pancreatic exocrine secretion through intraduodenal serine proteases. ${ }^{12}$ In a subset of patients it seems that the pancreas is under constant stimulation by CCK..$^{29}$ A CCK releasing peptide has been identified that resides in the proximal small intestine and is degraded by the serine proteases. As patients with chronic pancreatitis have decreased protease activity they may be unable to inactivate this releasing enzyme leading to perpetual pancreatic stimulation. These pathophysiological mechanisms illustrate the importance of exogenous protease to allow the pancreas to rest and afford pain relief.

To achieve feedback inhibition and thus have an impact on pain it is necessary to deliver exogenous protease to the 
proximal small intestine as the serine proteases and CCK peptide are found there. There have been six randomised trials with 193 patients examining the use of pancreatic enzyme preparations. The two trials using non-enteric coated preparations were shown to be effective ${ }^{31} 32$ while the four studies using enteric coated preparations were ineffective in reducing pain..$^{33-36}$ This illustrates the importance of using non-enteric coated preparations for the treatment of chronic pancreatitic pain. As these preparations are non-enteric coated, however, they are susceptible to degradation in the stomach by gastric acids and may be degraded before reaching the duodenum. For this reason, an acid suppressing agent such as an $\mathrm{H}_{2}$ receptor antagonist or proton pump inhibitor should be added. A regimen of non-enteric coated enzymes taken orally with meals and at bedtime provides good clinical response in most patients.

The clinical course of patients with chronic pancreatitis receiving pancreatic enzyme replacement has yet to be fully delineated. Certainly the greatest success is seen in patients with small duct disease as this has been effective in decreasing abdominal pain in about $70 \%$ of these patients as compared with $25 \%$ of large duct disease. If a patient is found to have small duct disease they should be initially tried on a one month trial of pancreatic enzyme replacement. If they respond, they should continue to be given this medication, but if they do not, an EUS or ERCP should be performed to examine for an inflammatory stricture or other lesion that may be corrected endoscopicaly or surgically. Patients that respond to therapy should typically continue on enzyme therapy until a six month pain free interval has been achieved. This is necessary as after the withdrawal of medications, about $50 \%$ of patients continue to do well with no further relapses, however the remainder do relapse. These patients are continued with enzyme therapy with typically good results. Clear predictors for success off of medications has yet to be defined.

\section{OCTREOTIDE}

Octreotide was initially selected and examined for the treatment of chronic pancreatitis secondary to its therapeutic potential in improving small and large duct disease. As it is a somatostatin analogue, this drug inhibits pancreatic secretion and considerably lowers CCK levels. Initially, there were a number of small short term studies examining the use of this drug, but these resulted in variable findings. ${ }^{37-40} \mathrm{~A}$ multicentre pilot study was performed in 1993 to examine various dosing regimens and showed that $200 \mu \mathrm{g}$ of octreotide taken subcutaneously three times daily was superior to placebo. ${ }^{41}$ Octreotide significantly relieves pain in many patients with severe chronic pancreatitis that is refractory to other forms of therapy. Predictors of response remain unclear at this time, but it probably acts through reduction in CCK levels.

\section{CHOLECYSTOKININ ANTAGONISTS}

Cholecystokinin, originally thought to be confined only to the gastrointestinal tract, is now known to be found in both the gastrointestinal tract and central nervous system. McCleane ${ }^{42}$ reported a novel treatment by treating patients with proglumide, a non-specific CCK receptor antagonist after noting that patients with abdominal pain from chronic pancreatitis had reduced analgesic response to morphine. He found that proglumide reversed tolerance to morphine analgesia, potentiated its effects, and even caused analgesia on its own. Based upon this, the author theorised that proglumide induced analgesia would be produced in chronic pancreatitis patients having raised CCK levels.

To evaluate the therapeutic efficacy of the CCK-A receptor antagonist, loxiglumide, a recent multicentre dose-response controlled trial was conducted in Japan. ${ }^{43}$ In this study, 207 patients with abdominal pain induced by chronic pancreatitis were randomly assigned to oral treatment with loxiglumide at differing doses or placebo for four weeks. The overall clinical improvement rate was $46 \%$ in the $300 \mathrm{mg}$ group, 58\% in the $600 \mathrm{mg}$ group, and $52 \%$ in the $1200 \mathrm{mg}$ group.

These studies only further reaffirm the importance of CCK in feedback regulation and offer another prospective treatment for the control of chronic pancreatitis induced abdominal pain.

\section{NERVE BLOCK}

Unfortunately, we are unable to successfully medically manage all cases of chronic pancreatitis pain and secondary to this other forms of pain relief have been explored. Historically, through a blind translumbar approach a typical combination of long acting local anaesthetics and corticosteroids have been injected into the celiac plexus. With the advent of newer technologies, this has been largely replaced by computed tomography (CT) guided and now EUS guided approaches. In 1999, Gress et al performed a randomised prospective comparison of 22 patients treated with either EUS guided coeliac axis block compared with CT guided block using bupivacaine and triamcinolone. The study found that EUS guided block provided more initial (50\% compared with $25 \%$ ) and persistent (30\% compared with $12 \%$ ) pain relief than CT guided blocks. ${ }^{44}$ In 2001, this same group prospectively examined 90 patients treated with coeliac axis block once again using bupivacaine and triamcinolone. They noted an initial response in overall pain scores in 55\% of patients, but only $26 \%$ at 24 weeks, and $10 \%$ at 24 weeks. ${ }^{45}$ As well it was noted that patients less than 45 years of age and those with prior pancreatic surgery were least likely to respond.

EUS guided coeliac axis block represents a comparatively safe and well tolerated option in the treatment of chronic pancreatitis pain. Given the fact that it is by nature invasive, with only short term benefits, and without long term follow up this procedure should be reserved for patients who have failed optimum medical management.

\section{OXIDATIVE STRESSES}

Stemming from the hypothesis that free radical formation may be contributing to pancreatic inflammation in chronic pancreatitis there have been two studies examining the use of antioxidants in this disorder. In the first, 20 patients with chronic pancreatitis were given antioxidant therapy (organic selenium, $\beta$ carotene, vitamin $\mathrm{C}$, and vitamin $\mathrm{E}$, and methionine) daily in a double blind crossover trial for 30 weeks. They found that 0 of 20 patients receiving treatment developed pain during the study as compared with 6 of 20 in the placebo group. ${ }^{46}$ This study was criticised for its methodology in the diagnosis of chronic pancreatitis in these patients however. In 2000, a small study of 10 patients treated for one year with daily antioxidants( L-methionine, $\beta$ carotene, vitamin $C$, vitamin $E$, and organic selenium) showed a significant decrease in pain scores. ${ }^{47}$ Unfortunately, these small studies while illustrating the possible benefits of antioxidant therapy fail to do so convincingly secondary to small sample sizes and questionable methodology. Given this, there is not significant current evidence to advocate or refute this treatment. Long term prospective randomised studies with significant power will be necessary to assess this further.

\section{ENDOSCOPIC TREATMENT}

Endoscopic pancreatic duct decompression via ERCP has been found to give pain relief in some patients. ${ }^{48-51}$ The principle behind this approach is that by decreasing ductal pressure as seen in sphincter of Oddi dysfunction or pancreatic duct strictures, pain relief can be attained. The 
largest body of evidence for this has been by Rosch et al in which 1018 patients were retrospectively identified and followed up for an average of five years after their therapeutic endoscopies. ${ }^{50}$ In this study, obstruction of the pancreatic duct was found to be secondary to stricture in $47 \%$, stones in $18 \%$, and both in $32 \%$. Endoscopic intervention consisted of pancreatic duct stricture dilatation, stone extraction, or pancreatic duct sphincterotomy. At the end of follow up, $60 \%$ had completed endoscopic therapy, 16\% were still receiving therapy, and $24 \%$ had undergone therapy. Pain relief was $86 \%$ in the entire group, but only $65 \%$ in an intent to treat analysis.

The role of endoscopic pancreatic therapy is evolving. Certainly, in patients who have failed optimal medical management it should be pursued before considering surgical options as about two thirds of patients with pancreatic duct strictures will benefit from this form of treatment.

\section{SURGERY}

Refractory pain in patients who fail optimal medical and endoscopic therapies is an indication for surgical intervention. Thoroscopic bilateral splanchnicectomy entails transecting the nociceptive fibres originating in the pancreatic area at the thoracic level. There have been small reports of the use of this technique for the treatment of pain from adrenal cancer and pancreatic cancer. The only large series study with long term follow up to examine this has been in 44 patients with a median follow up of 36 months. In this series, pain scores significantly improved postoperatively, but at five years about $50 \%$ of patients had pain recurrence. ${ }^{52}$

Surgical decompression is typically considered in refractory pain in the presence of pancreatic ductal dilatation $>6 \mathrm{~mm}$ secondary to technical issues. Ductal decompression may be accomplished by the Puestow procedure (lateral pancreaticojejunostomy). There have been many variations of this procedure that preserve the duodenum and pylorus that have been used with varying results. ${ }^{53-56}$ Most studies initially report $80 \%$ pain relief, but long term pain relief occurs in only $30 \%-50 \%$.

In recent years the operative morbidity and mortality for these procedures has improved. A study examining 231 pancreatic cancer resections that has been extrapolated to chronic pancreatitics has shown an operative mortality of $0.4 \%{ }^{57}$ Another showed good quality of life and low morbidity after the procedure. ${ }^{58}$ This makes these procedures viable options in the treatment of refractory pain.

\section{PANCREATECTOMY AND AUTOLOGOUS ISLET CELL TRANSPLANTATION}

The first autologous islet cell transplantation was performed in 1977 on a 39 year old patient with familial chronic pancreatitis. ${ }^{59}$ Since that time, according to 2001 data from the International Islet Transplant Registry, only 140 islet cell autotransplants after pancreatectomy were performed between 1990 and 2001. ${ }^{60}$ The current approach entails infusion of isolated islet cells after pancreatectomy into the portal vein with the goal of achieving decreased pain and decreased insulin requirements.

The first large series of patients was reported by the University of Minnesota, summarising the results in 48 patients undergoing the procedure between 1977 and 1995. ${ }^{59}$ Of the 39 evaluable patients, 51\% were insulin independent for at least one month, with the probability of sustained insulin independence decreasing to $34 \%$ after two years. However, of the 18 patients who received an autotransplant with islets prepared with the most recent techniques in islet cell isolation, the long term success rate was 55\%. The most powerful predictor of insulin independence was the number of islet cells infused, which in turn is inversely related to the degree of fibrosis of the pancreas.

More recently, Rilo et al reviewed 22 cases performed at the University of Cincinnati. ${ }^{61}$ In this small experience, at 19 months, $82 \%$ of patients were completely off narcotics (mean 78.4 (SD 105.9) morphine equivalents preoperatively compared with 9.5 (24) morphine equivalents postoperatively). In addition, $41 \%$ of patients were insulin free, $27 \%$ required fewer than 10 units/day, and the remaining $27 \%$ required 15 to 40 units/day postoperatively. Another study to examine this topic evaluated 40 patients with follow up ranging from six months to seven years. ${ }^{62}$ In this study, at two years after transplant, median HbAlc was $6.6 \%$ and median insulin requirement was 12 units/day as compared with six year data with median HbAlc of $8 \%$ and median insulin requirement was 43 units/day. In addition, most patients no longer required opioid analgesia and 68\% were able to return to work.

In a follow up study, detailing their experience to date, the University of Minnesota reported data regarding 64 additional pancreatectomies and islet cell autotransplants performed since there initial study. ${ }^{63}$ In this study, as was previously suggested, insulin independence was directly correlated with the number of islet equivalents $/ \mathrm{kg}$ body weight infused. Complete insulin independence was achieved in $71 \%$ of patients without prior pancreatic surgery and in $100 \%$ of patients with a prior Whipple procedure. Furthermore, during subgroup analysis, patients with an islet yield of $>2500$ islet equivalents $/ \mathrm{kg}$ body weight were found to have an $85 \%$ chance of complete insulin independence. Pain after pancreatectomy was found to be unchanged or worsened in $12 \%$, improved in $32 \%$, and resolved in $32 \%$.

Pancreatectomy with autologous islet cell transplantation has been proposed as a therapy for pain associated with chronic pancreatitis. As can be seen from the few studies to date there is a wide variance in results regarding its efficacy in treating pain. It may be considered as a last option in patients with refractory pain who have failed conventional medical, endoscopic, and surgical options. Use in this subset of patients seems justified, however, this in itself is problematic as we now know that insulin independence is directly correlated to the amount of islet cells transplanted. Therefore the patients who have benefited most from this procedure to date have chronic pancreatitis without prior pancreatic surgery or evidence of islet cell insufficiency. The role of this procedure will still have to be further defined, but based upon current studies islet cell autotransplantation may be an option in lieu of ductal decompression surgery or partial pancreatic resection in patients with intractable painful small duct disease, particularly as the standard surgical procedures lead to decreased islet cell yield.

\section{CONCLUSION}

Chronic pancreatitis is an inflammatory condition with a poorly understood pathogenesis, multiple aetiologies, and varied presentations ranging from abdominal pain to steatorrhoea. These factors, have led to the ultimate under recognition of this disorder. Furthermore, for those who are recognised as having this disorder, the treatment has unfortunately been confusing and frustrating for clinicians and patients alike. Regrettably, the situation is often only exacerbated through alcohol and narcotics dependence as it is commonly seen in these patients.

Before beginning treatment regimens it is important to ascertain the aetiology of the disease and define it in regards to large duct compared with small duct disease as this will affect the treatment course. While large duct disease is easily recognised by a myriad of available testing, the diagnosis of small duct chronic pancreatitis requires the use of specialised 
testing (direct hormone stimulation test) that may not be available in local communities.

A firm understanding of CCK homoeostasis and its impact on pancreatic feedback inhibition is necessary to appreciate the role of pancreatic proteases, octreotide, and CCK antagonists in the treatment of painful chronic pancreatitis. With an understanding of the pathophysiology surrounding the disorder, comes a systematic approach to the diagnosis and treatment of these patients.

\section{Authors' affiliations}

V Gupta, P P Toskes, University of Florida, Division of Gastroenterology, Hepatology and Nutrition, Gainesville, Florida, USA

Funding: none.

Competing interests: none.

\section{REFERENCES}

1 Steer ML, Waxman I, Freedman S. Chronic pancreatitis. N Engl J Med 1995;332:1482-90.

2 Layer $\mathbf{P}$, Yamamoto $\mathrm{H}$, Kalthoff $\mathrm{L}$, et al. The different courses of early and late onset idiopathic and alcoholic pancreatitis. Gastroenterology 1994; 107:1481-7.

3 Toskes PP, Hansell J, Cerda J, et al. Vitamin B12 malabsorption in chronic pancreatic insufficiency. N Engl J Med 1971;284:627-32.

4 Anderson NN, Pedersen NT, Scheel J, et al. Incidence of alcoholic chronic pancreatitis in Copenhagen. Scand J Gastroenterol 1982;17:247-52.

5 Copenhagen pancreatitis study. An interim report from a prospective multicentre study. Scand J Gastroenterol 1981;16:305-12.

6 Walsh TN, Rode J, Theiss BA, et al. Minimal change chronic pancreatitis. Gut 1992;33:1566-71.

7 Okazaki, K. Autoimmune pancreatitis is increasing in Japan. Gastroenterology 2003;125:1557.

$8 \mathrm{Kim} \mathrm{KP}, \mathrm{Kim} M H$, Lee SS, et al. Autoimmune pancreatitis: it may be a worldwide entity. Gastroenterology 2004;126:1214.

9 Cohn JA, Bornstein JD, Jowell PS. Cystic fibrosis mutations and genetic predisposition to idiopathic chronic pancreatitis. Med Clin North Am 2000 May;84:621-31.

10 Freiss $H$, Yamanaka Y, Buchler $M$, et al. Increased expression of acidic and basic fibroblast growth factors in chronic pancreatitis. Am J Pathol 1994; 144:117-28.

11 Di Sebastiano P, di Mola FF, Di Febbo C, et al. Expression of interleukin 8 (IL8 ) and substance $P$ in human chronic pancreatitis. Gut 2000;47:423-8.

12 Chey WY. Neurohormonal control of the exocrine pancreas. Curr Opin Gastroenterol 1997:13:375-80.

13 Hayakawa T, Kondo T, Shibata T, et al. Relationship between pancreatic exocrine function and histological changes in chronic pancreatitis. Am J Gastroenterol 1992;87:1170-4.

14 Somogyi L, Ross S, Cintron M, et al. Comparison of biologic porcine secritin, synthetic porcine secretin, and synthetic human secretin in pancreatic function testing. Pancreas 2003;27:230-4

15 Forsmark CE, Toskes PP. What does an abnormal pancreatogram mean? Gastrointest Endosc Clin N Am 1995;5:105-23.

16 Toskes PP. Update on diagnosis and management of chronic pancreatitis. Curr Gastroenterol Rep 1999;1:145-53.

17 Freeman ML, DiSario JA, Nelson DB, et al. Risk factors for post-ERCP pancreatitis: a prospective, multicenter study. Gastrointest Endosc $2001 ; 54: 425-34$

18 Williams DB, Hoffman BJ. Complications of interventional endoscopic ultrasonography. In: Bhutani M, ed. Interventional endoscopic ultrasonography. Amsteldijk, the Netherlands: Harwood Academic 1999:151-8

19 Hollerbach S, Klamann A, Topalidis T, et al. Endoscopic ultrasonography (EUS) and fine needle aspiration (FNA) cytology for diagnosis of chronic pancreatitis. Endoscopy 2001;33:824-31.

20 Zimmermann MJ, Mishra G, Lewin DN, et al. Comparison of EUS findings with Histopathology in chronic pancreatitis. Gastrointest Endosc 1997; 45:A185

21 Chowdhury RS, Bhutani MS, Mishra G, et al. Comparative analysis of pancreatic function testing versus morphologic assessment (by EUS) for the evaluation of chronic unexplained abdominal pain. Gastroenterology 2001;120:A647.

22 Raimondo M, Wiersema MJ, Vazquez-Sequeiros E, et al. Endoscopic ultrasound may not be as sensitive as previously thought to diagnose chronic pancreatitis. A preliminary correlation study with CCK pancreatic function tests. Gastrointest Endosc 2001;53:A69.

23 Amann ST, Bishop M, Curington C, et al. Fecal pancreatic elastase 1 is inaccurate in the diagnosis of chronic pancreatitis. Pancreas 1996;13:226-30.

24 Jacobson DG, Curington C, Connery K, et al. Trypsin-like immunoreactivity as a test for pancreatic insufficiency. N Engl J Med 1984;310:1307-9.

25 Ammann RW, Akovbiantz A, Largiader F, et al. Course and outcome of chronic pancreatitis. Gastroenterology 1984;86:820-88.
26 Lankisch PG, Seidensticker F, Lohr-Happe A, et al. The course of pain is the same in alcohol and non alcohol induced chronic pancreatitis. Gastroenterology 1994;107:1481-7.

27 Chowdhury RS, Forsmark CE, Davis RH, et al. Prevalence of gastroparesis in patients with small duct chronic pancreatitis. Pancreas 2003;26:235-8.

28 Singh V, Verne GN, Toskes P. Abdominal pain (AP) from gastroparesis is indistinguishable from (AP) from chonic pancreatitis. Gastroenterology 2003;124(suppl 1):W112.

29 Slaff J, Wolfe MM, Toskes PP. Elevated fasting cholecystokinin levels in pancreatic exocrine impairment: evidence to support feedback regulation. $J$ Lab Clin Med 1985;105:282-5

30 Mossner J. Palliation of pain in chronic pancreatitis: use of enzymes. (Abstract). Surg Clin North Am 1999:79:861-72.

31 Slaff J, Jacobson D, Tillman CR, et al. Protease-specific suppression of pancreatic exocrine secretion. Gastroenterology 1984;87:44-52.

32 Isaksson G, Ihse I. Pain reduction by an oral pancreatic enzyme preparation in chronic pancreatitis. Dig Dis Sci 1983;28:97-102.

33 Halgreen $\mathrm{H}$, Pederson NT, Worning $\mathrm{H}$. Symptomatic effect of pancreatic enzyme therapy in patients with chronic pancreatitis. Scand J Gastroenterol 1986;21:104-8.

34 Mossner J, Secknus R, Meyer J, et al. Treatment of pain with pancreatic extracts in chronic pancreatitis: results of a prospective placebo-controlled multicenter trial. Digestion 1992;53:54-66.

35 Malesci A, Gaia E, Fioretta A, et al. No effect of long-term treatment with pancreatic extract on recurrent abdominal pain in patients with chronic pancreatitis. Scand J Gastroenterol 1995:30:392-8.

36 Larvin M, McMahon M, Thomas WEG, et al. Creon (enteric coated pancreatin microspheres) for the treatment of pain in chronic pancreatitis: a double-blind randomized placebo-controlled crossover study. Gastroenterology 1991;100:A283.

$37 \mathrm{Uhl}$ W, Anghelacopoulos SE, Friess $\mathrm{H}$, et al. The role of octreotide and somatostatin in acute and chronic pancreatitis. Digestion 1999;60(suppl 2):23-31.

38 Malfertheiner $\mathbf{P}$, Mayer D, Buchler $M$, et al. Treatment of pain in chronic pancreatitis by inhibition of pancreatic secretion with octreotide. Gut 1995;36:450-4.

39 Buchler MW, Binder M, Friess $H$. Role of somatostatin and its analogues in the treatment of acute and chronic pancreatitis. Gut 1994;35(suppl 3):S15-19.

40 Schmalz MJ, Soergel KH, Johanson JF. The effect of octreotide acetate (Sandostatin) on the pain of chronic pancreatitis. Gastroenterology 1992;102:A290.

41 Toskes PP, Forsmark CE, DeMeo MT, et al. A multi-center controlled trial of octreotide for the pain of chronic pancreatitis. (Abstract). Pancreas 1993;8:774.

$42 \mathrm{McCleane} \mathrm{GJ}$. The cholecystokinin antagonist proglumide has an analgesic effect in chronic pancreatitis. Pancreas 2000;21:324-5.

43 Shiratori K, Takeuchi T, Satake K, et al. Clinical evaluation of oral administration of a cholecystokinin-a receptor antagonist (loxiglumide) to patients with acute, painful attacks of chronic pancreatitis: a multicenter doseresponse study in Japan. Pancreas 2002;25:E1-5.

44 Gress F, Schmitt C, Sherman S, et al. A prospective randomized comparison of encloscopic ultrasound- and computed tomography-guided celiac plexus block for managing chronic pancreatitis pain. Am J Gastroenterol 1999:94:900-5.

45 Gress F, Schmitt C, Sherman S, et al. Endoscopic ultrasoundguided celiac plexus block for managing abdominal pain associated with chronic pancreatitis: a prospective single center experience. Am J Gastroenterol 2001;96:409-16

46 Uden S, Bilton D, Nathan L, et al. Antioxidant therapy for recurrent pancreatitis: placebo-controlled trial. Aliment Pharmacol Ther 1990;4:357-71.

47 De las Heras Castano G, Garcia de la Paz A, Fernandez MD, et al. Use of antioxidants to treat pain in chronic pancreatitis. Rev Esp Enferm Dig 2000:92:375-85.

48 Okolo PI 3rd, Pasricha PJ, Kalloo AN. hat are the long-term results of endoscopic pancreatic sphincterotomy? Gastrointest Endosc 2000:52:15-19.

49 Geenen JE, Rolny P. Endoscopic therapy of acute and chronic pancreatitis. Gastrointest Endosc 1991;37:377.

50 Choudari CP, Nickl NJ, Fogel E, et al. Hereditary pancreatitis: clinical presentation, ERCP findings, and outcome of endoscopic therapy. Gastrointest Endosc 2002;56:66-71.

51 Rosch T, Daniel S, Scholz M, et al. Endoscopic treatment of chronic pancreatitis: a multicenter study of 1000 patients with long-term follow-up. Endoscopy 2002;34:765-71

52 Buscher HC, Jansen JB, Van Dongen R, et al. Results of bilateral thoracic splanchnicectomy in patients with chronic pancreatitis. $\mathrm{Br} J$ Surg 2002;89:158-62

53 Massucco $P$, Calgaro M, Bertolino F, et al. Outcome of surgical treatment for chronic calcifying pancreatitis. Pancreas $2001 ; 22: 378-82$.

54 Friess $\mathrm{H}$, Berberat PO, Wirtz $M$, et al. Surgical treatment and long-term follow-up in chronic pancreatitis. Fur J Gastroenterol Hepatol 2002; 14:971-7.

55 Sakorafas GH, Farnell MB, Farley DR, et al. Long-term results after surgery for chronic pancreatitis. Int J Pancreatol 2000;27:131-42.

56 Izbicki JR, Bloechle C, Knoefel WT, et al. Surgical treatment of chronic pancreatitis and quality of life after operation. Surg Clin North Am 1999;79:913-44. 
57 Fernandez-del Castillo C, Rattner DW, Warshaw AL. Standards for pancreatic resection in the 1990s. Arch Surg 1995;130:295-300.

58 McLeod RS, Tayor BR, O'Connor BI, et al. Quality of life, nutritional status, and gastrointestinal hormone profile following the whipple procedure. Am J Surg 1995:169:179-85.

59 Wahoff DC, Papalois BE, Najarian JS, et al. Autologous islet transplantation to prevent diabetes after pancreatic resection. Ann Surg 1995;222:562-79.

60 International Islet Transplant Registry. Newsletter no 9, 2001;8, 1 .
61 Rodriguez Rilo HL, Ahmad SA, D'Alessio D, et al. Total pancreatectomy and autologous islet cell transplantation as a means to treat severe chronic pancreatitis. J Gastrointest Surg 2003;7:978-89.

62 Clayton HA, Davies JE, Pollard CA, et al. Pancreatectomy with islet autotransplantation for the treatment of severe chronic pancreatitis: the first 40 patients at the leicester general hospital. Transplantation 2003;76:92-8.

63 Gruessner RW, Sutherland DE, Dunn DL, et al. Transplant options for patients undergoing total pancreatectomy for chronic pancreatitis. $J$ Am Coll Surg 2004; 198:559-67.

\section{IMAGES IN MEDICINE}

\section{Dermatology spot diagnosis}

A 25 year old otherwise healthy man presented with painless lesions on the palmar side of both hands (fig lA) and elbows (fig 1B). He was not taking any medication and his family history was negative. Laboratory studies disclosed the following values: total cholesterol $24.0 \mathrm{mmol} / \mathrm{l}$ (N: 3.8-5.2), triglycerides $17.4 \mathrm{mmol} / \mathrm{l}(\mathrm{N}: 0.6-$ $2.3)$, HDL-C $0.80 \mathrm{mmol} / \mathrm{l}(\mathrm{N} \geqslant 0.90)$. Serum was lactescent at $4^{\circ} \mathrm{C}$ after a night in hospital. Serum aspartate aminotransferase, alanine aminotransferase, and thyroid stimulating hormone were normal. A lipoprotein electrophoresis showed the presence of a broad $\beta$ band (cholesterol enriched chylomicron and VLDL remnants). The apo E genotype was confirmed to be E2/E2. Dysbetalipoproteinaemia (type III hyperlipoproteinaemia, broad-beta disease, or remnant removal disease) is a rare disorder affecting 1:5000 to 1:10 000 persons and is in part attributable to a mutation in the APOE gene resulting in reduced uptake of apo E-containing lipoproteins by the liver and impaired conversion of VLDL and IDL to LDL. ${ }^{2}$ The manifestations include tuberous xanthomas, deposits of cholesterol in the palmar creases (also called striae palmaris or xanthoma striata palmaris), and severe mixed hyperlipidaemia. ${ }^{3}$ Risk of atherosclerosis and its complications is increased, with onset in the fourth and fifth decade. Hypothyroidism and diabetes are known to be precipitating factors. Treatment of this condition is essentially lipid lowering diet complemented with lipid lowering drug treatment and avoidance of alcohol, oestrogens, and triglyceride raising agents. ${ }^{4}$ The patient was treated with a fibrate and a HMG CoA reductase inhibitor; his xanthomas have completely regressed.

P Maheux

Division of Endocrinology and Metabolism, Université de Sherbrooke, 3001 12th Avenue North, Sherbrooke, Québec, Canada

$\mathrm{J} 1 \mathrm{H} 5 \mathrm{~N} 4$;

Pierre.Maheux@USherbrooke.ca

\section{REFERENCES}

1 Mahley R, Rall S. Type III hyperlipoproteinemia (dysbetalipoproteinemia): the role of apolipoprotein $\mathrm{E}$ in normal and abnormal lipoprotein metabolism. In: Scriver CR, Beaudet AL, Valle D, et al, eds. The metabolic and molecular bases of inherited disease. 8th ed. New York: McGraw-Hill, 2001:2753.

2 Mahley RW, Huang Y, Rall SC Jr. Pathogenesis of type III hyperlipoproteinemia (dysbetalipoproteinemia): questions, quandaries, and paradoxes. J Lipid Res 1999;40:1933-49.
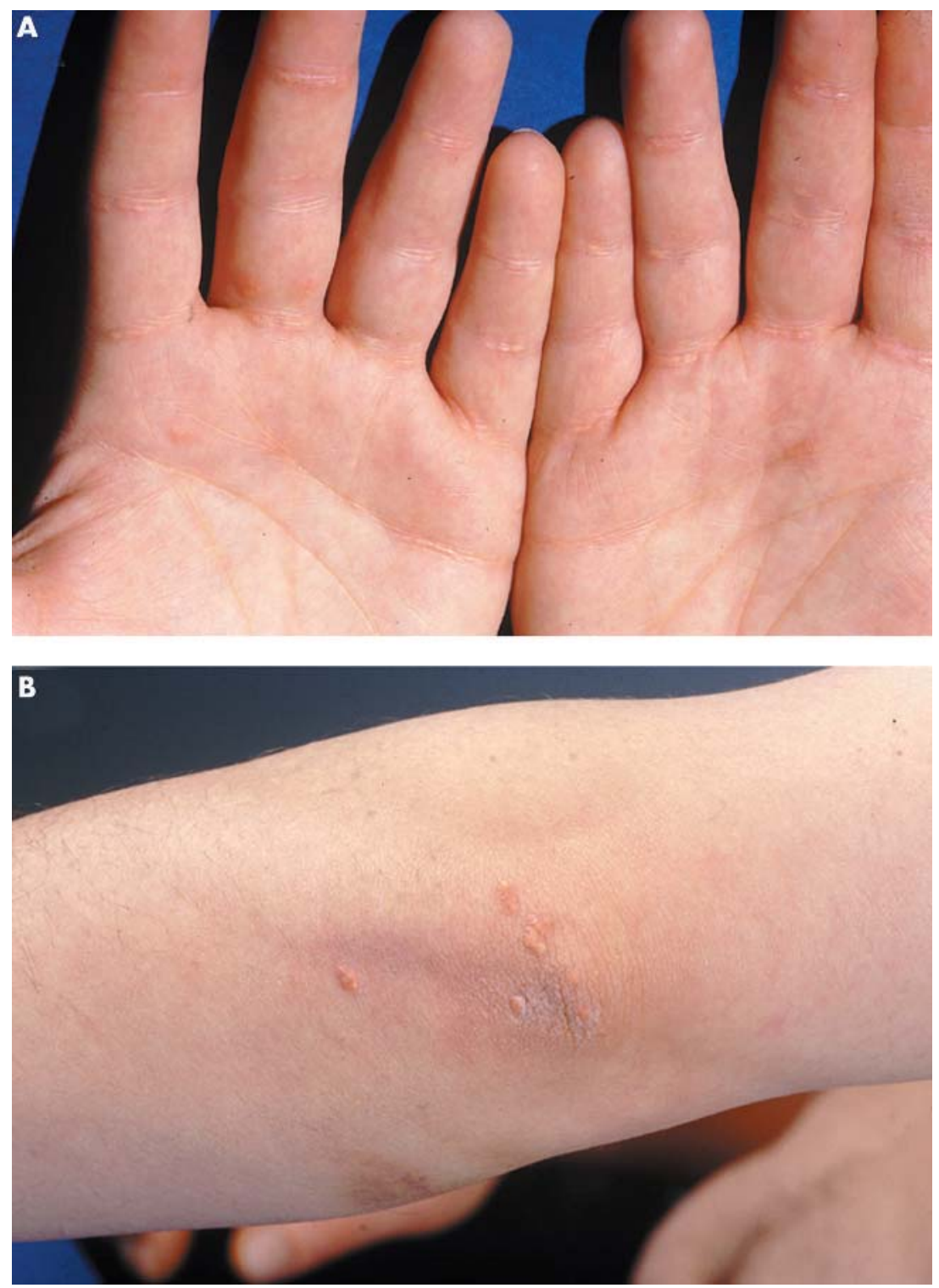

Figure 1 (A) Lesions on palmar face of both hands and (B) papules on extension side of left elbow (obtained with patient's permission).

3 Cruz PD Jr, East C, Bergstresser PR. Dermal, subcutaneous, and tendon xanthomas: diagnostic markers for specific lipoprotein disorders. J Am Acad Dermatol 1988;19:95-111.

4 Civeira F, Cenarro A, Ferrando J, et al. Comparison of the hypolipidemic effect of gemfibrozil versus simvastatin in patients with type III hyperlipoproteinemia. Am Heart J 1999;138:156-62. 